\title{
Prevalence of and factors associated with enamel fracture and other traumas in Brazilian children 8-10 years old
}

\section{Fernanda Bartolomeo FREIRE-MAIA ${ }^{(a)}$ Sheyla Márcia AUAD(a) \\ Mauro Henrique Nogueira \\ Guimarães de ABREU(b) \\ Fernanda SARDENBERG(a) \\ Milene Torres MARTINS(c) \\ Saul Martins PAIVA ${ }^{(a)}$ \\ Isabela Almeida PORDEUS(a) \\ Miriam Pimenta VALE(a)}

(a) Universidade Federal de Minas Gerais UFMG, School of Dentistry, Department of Paediatric Dentistry and Orthodontics, Belo Horizonte, MG, Brazil.

(b) Universidade Federal de Minas Gerais UFMG, School of Dentistry, Department of Community and Preventive Dentistry, Belo Horizonte, MG, Brazil.

(c) Universidade Estadual de Montes Claros - Unimontes, School of Dentistry, Department of Paediatric Dentistry, Montes Claros, MG, Brazil.

Declaration of Interests: The authors certify that they have no commercial or associative interest that represents a conflict of interest in connection with the manuscript.

\section{Corresponding Author:}

Fernanda Bartolomeo Freire-Maia

E-mail: fernandabartolomeo@gmail.com

hitps://doi.org/10.1590/1807-3107bor-2018.vol32.0089

Submitted: June 08, 2017

Accepted for publication: July 04, 2018

Last revision: July 18, 2018
Abstract: The aim of this study was to assess the prevalence and discriminate the associated factors between enamel fractures and other trauma/trauma sequelae in 8 to 10-year-old Brazilian schoolchildren. A representative sample of 1,201 children from public and private schools were enrolled in this cross-sectional study. Questionnaires about sociodemographic characteristics were answered by parents. The outcome variable (traumatic dental injury, TDI) was multi-categorized. Independent individual variables were sex, age, number of residents in household, parents/caregivers' level of education, family income, dental caries, and overjet. Type of school was considered an independent contextual variable. Multilevel analysis, bivariate, and multivariate multinomial logistic regression models were performed. The prevalence of TDI was $14.0 \%$ ( $2.8 \%$ with other trauma/trauma sequelae). The multilevel analysis revealed no significant difference between the type of school and TDI. The multinomial logistic regression showed that boys (OR $=2.3$; 95\%CI: 1.1-4.8), older children (OR = 1.8; 95\%CI: 1.1-3.0) and individuals with an overjet $>3 \mathrm{~mm}(\mathrm{OR}=2.5$; 95\%CI: 1.0-6.2) were more likely to present other trauma/trauma sequelae. Enamel fracture was not significantly associated with any variables. The prevalence of TDI in 8 to 10 -year-old schoolchildren was $14 \%$ but only $2.8 \%$ of other trauma/trauma sequelae. Differences regarding the associated factors of TDI involving enamel fracture or other trauma/trauma sequelae were detected, suggesting that the different TDI classification cannot be evaluated as a single category.

Keywords: Tooth Injuries; Child; Dentition, Permanent.

\section{Introduction}

Traumatic dental injury (TDI) can be an irreversible oral condition characterized by life-long debilitating effects, such as pain and aesthetic, psychological, social, therapeutical, and financial problems. ${ }^{1}$ In addition, TDI might also impact on the oral health-related quality of life (OHRQoL) of young patients and their families. ${ }^{2,3}$ TDI in permanent teeth is a common oral disorder, and according to a recent meta-analysis, is estimated to affect around $20 \%$ of children, ${ }^{4}$ being most frequent in 8 to 10 -year-old individuals. 5,6 TDI can vary from a small concussion or enamel fracture, to complicated crown fractures or large displacements, 
and to tooth loss. ${ }^{7}$ Although enamel fractures have minor consequences and may not even be noticed by the affected individuals and their families, ${ }^{8,9,10,11,12}$ other trauma, considerably more visible and/or severe, may be considered a serious public oral health problem. ${ }^{13}$

Despite the different consequences of enamel fracture and other trauma, there are few studies assessing those differences, especially in children aged 8 to 10 years. Most previous studies assessing TDI focused on a binary outcome (present or absent) including enamel fracture in the same category of other trauma. ${ }^{9,10}$ There are few published statistical models available that evaluate the prevalence of and factors associated with TDI classifying this outcome in multiple categories of severity. ${ }^{14,15}$

Studies addressing the prevalence and associated factors of oral disorders are vital for the establishment of preventive and/or educative measures in the public healthcare system. Indeed, there has been a need for the development of evidence-based recommendation to guide public authorities and oral healthcare policy makers. Therefore, the aim of this study was to assess the prevalence and discriminate the associated factors between enamel fracture and other trauma in 8 to 10-year-old children.

\section{Methodology}

\section{Ethical issues}

The research project was approved by the Human Research Ethics Committee of the Universidade Federal de Minas Gerais, Belo Horizonte, Brazil (Parecer $n^{\circ}$. 0465.0.203.000-09). Written statements of consent were read and signed by parents/caregivers and children prior to their participation in the study. The present study was part of a previous crosssectional survey in which other outcomes were measured, such as dental caries and malocclusion. ${ }^{16,17}$

\section{Sampling and setting}

A cross-sectional study was conducted involving a representative sample of 1,201 schoolchildren aged 8 to 10 years, randomly selected through a multistage sampling method from an initial population of 97,487 children, registered at public and private schools of Belo Horizonte, from April to October 2010. Belo Horizonte is the capital of the state of Minas Gerais, which is located in the southeastern region of Brazil, and has a population of approximately 2,375,151 inhabitants distributed across nine administrative districts. ${ }^{18}$ Type of school (public and private) was considered a contextual variable. In Brazil, type of school is indicator of socioeconomic condition where children from higher socioeconomic conditions generally attend private schools and children from lower socioeconomic conditions mainly attend public schools. ${ }^{16}$

To ensure representativeness, the sample was stratified according to the nine administrative districts. The first stage was the randomization of public and private schools in each administrative district of the city. In the second and third stages, classes and children were randomly chosen from the selected schools (proportionally to the total number of children enrolled in the schools).

\section{Sample size calculation}

A sample of 1,201 children allowed a power of 99.9\%, and 95\% confidence interval (CI), based on a previous Brazilian study on association between dental trauma with overjet (overjet $<3 \mathrm{~mm}$ : $13.1 \%$, overjet > 3mm: $28.6 \%) .{ }^{19}$

\section{Eligibility criteria}

The inclusion criteria consisted of children aged 8 to 10 years and the presence of upper and lower permanent incisors. The exclusion criteria were children wearing fixed orthodontic appliance and with cognitive disorders, according to the report of their teachers.

\section{Pilot study and calibration}

A pilot study was carried out to test the feasibility of the study, the dental examination, and the questionnaires; the method proposed was feasible. The examination was carried out by two dentists who were previously trained and calibrated for each clinical condition. The calibration process involved theoretical and clinical exercises. ${ }^{16,17}$ TDI was evaluated through Andreasen criteria. ${ }^{20}$ The Dental Aesthetic Index (DAI) criteria were 
used for malocclusion. ${ }^{21}$ In this study, however, for malocclusion assessment, only overjet was considered. ${ }^{22}$ Inter-examiner kappa ranged from 0.71 to 1.00 after examination of 70 children $(\mathrm{TDI}=0.71$; malocclusion $=1.00$ ). Intra-examiner kappa values were between 0.90 and 1.00 after examination of 50 children two weeks later $(\mathrm{TDI}=0.90 ; 0.91$; malocclusion $=0.93 ; 1.00) .{ }^{23}$

\section{Data collection}

Clinical data such as TDI and overjet were collected by clinical examination carried out in schools. The oral examination was performed in classrooms by two dentists previously calibrated, using sterile clinical mirrors and wooden spatulas, under natural light; radiographs were not taken. The dependent variable of interest (TDI) was categorized in no trauma, enamel fracture, and other trauma/trauma sequelae (which included: enamel-dentin fracture with or without pulp involvement, lateral luxation, intrusion, extrusion, avulsion, teeth discoloration and filling of fractured teeth). ${ }^{20}$

Parents/caregivers answered a self-administered structured questionnaire that included demographic and socioeconomic variables. The sociodemographic data included sex, age, family income, number of residents in household, and parents/caregivers level of education. Family income used the current Brazilian Monthly Minimum Wage in 2010 (BMMW $=\mathrm{U} \$ 258.33$ ). Level of education was measured in number of school years (Figure 1). They were not asked about their children's dental status. Therefore, there was no comparison between questionnaires' data and clinical data.

\section{Statistical analyses}

Data were analyzed using the Hierarchical Linear and Nonlinear Modeling (HLM for Windows, version 6.06, Scientific Software International Inc., USA) to perform multilevel analyses and the Statistical Package for the Social Sciences (SPSS for Windows, version 19.0, SPSS Inc., Chicago, IL, USA) for descriptive, bivariate, and multivariate multinomial logistic regression analyses. This study used "no trauma" as the reference category. The "enamel fracture" and "other trauma/trauma sequelae" categories were compared with "no trauma". ${ }^{14}$

In the first step, multilevel analyses were used to evaluate the association of contextual and individual variables with enamel fracture and other trauma/ trauma sequelae. ${ }^{24}$ Following the descriptive analysis, bivariate multinomial logistic regression models were developed individually to identify explanatory variables (sex, children's age, family income, number of residents in household, parents/caregivers level of education, and overjet) associated with the outcomes. Variables with $p$ value lower than 0.20 were included in the multivariate multinomial logistic regression. Independent variables that did not present significant association with the outcome variable were removed from the model one by one, in least significance order. Explanatory variables with $p$ value lower than 0.05

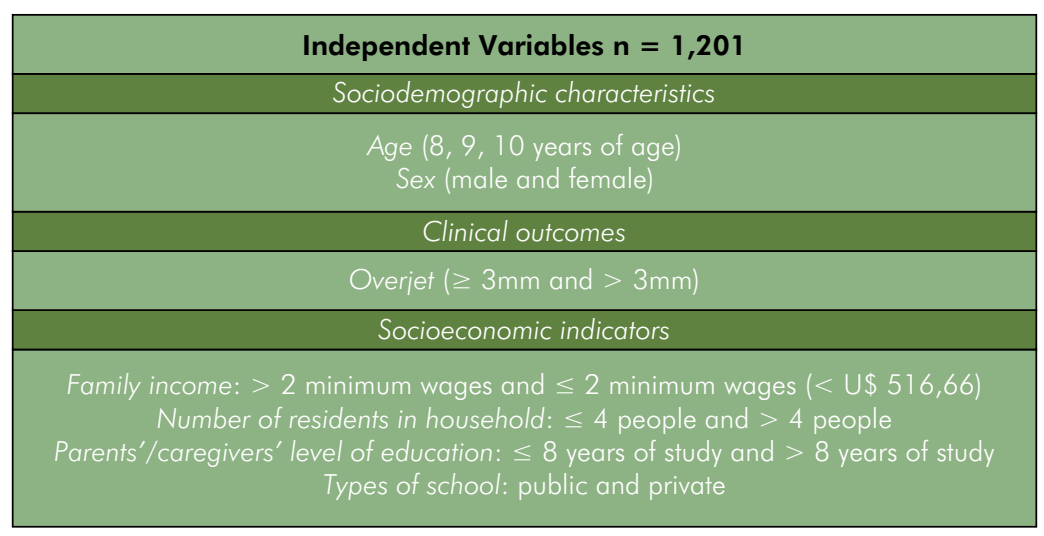

Figure. Explanatory variables. 
were maintained in the final model. Adjusted odds ratios $(95 \% \mathrm{CI})$ were also calculated. ${ }^{16,23}$

\section{Results}

Out of the 1,201 schoolchildren, 44.6\% were boys. The mean age was 9.8 years $(S D=0.80)$. Table 1 shows information about distribution of dependent and independent variables among participants. The prevalence of children with TDI was $14 \%: 11.2 \%$ with enamel trauma $(n=135)$ and $2.8 \%$ with other trauma/trauma sequelae $(n=34)$. Two hundred and four permanent teeth (204) were involved. Most of the children with TDI had only one affected tooth $(139 ; 82.2 \%) ; 27$ (16.0\%) had two teeth affected, and three children $(1.8 \%)$ had three teeth affected.
The maxillary central incisors were the teeth most frequently affected (68.1\%). The most frequent type of TDI was enamel fracture (81.4\%), followed by fractured enamel-dentin (8.3\%), complicated crown fracture $(2.6 \%)$, discoloration (2.6\%), avulsion $(1.5 \%)$, and $7.8 \%$ children had restorative treatment on the traumatized teeth. The most prevalent other trauma/ trauma sequelae was enamel-dentin fracture without pulp involvement (44.7\%).

Table 2 shows the analyses of the final estimation of variance components of the "null model" in the multilevel approach, which revealed no significant difference between type of school (public or private) and enamel fracture and other trauma/trauma sequelae in permanent teeth $(p>0.05)$. Therefore, type of school was not included in the bivariate and multivariate multinomial logistic regression analyses.

Table 1. Frequency of independent variables for the total sample and by types of TDI ( $n=1,201)$, Belo Horizonte, 2010.

\begin{tabular}{|c|c|c|c|c|}
\hline Variable & Total & No trauma & Enamel trauma & Other trauma/trauma sequelae \\
\hline \multicolumn{5}{|l|}{ Sex } \\
\hline Female & $536(44.6 \%)$ & $582(87.5 \%)$ & $71(10.7 \%)$ & $12(1.8 \%)$ \\
\hline Male & $665(55.4 \%)$ & 450 (84.0\%) & $64(11.9 \%)$ & $22(4.1 \%)$ \\
\hline \multicolumn{5}{|c|}{ Age (years) } \\
\hline 8 & $338(28.1 \%)$ & $300(88.8 \%)$ & $32(09.5 \%)$ & $6(1.8 \%)$ \\
\hline 9 & 427 (35.6\%) & $370(86.7 \%)$ & $50(11.7 \%)$ & $7(1.6 \%)$ \\
\hline 10 & $436(36.3 \%)$ & $362(83.0 \%)$ & $53(12.2 \%)$ & $21(4.8 \%)$ \\
\hline \multicolumn{5}{|c|}{ Overjet (mm) } \\
\hline$\leq 3$ & 1105 (92.1\%) & $951(86.1 \%)$ & $127(11.5 \%)$ & $27(2.4 \%)$ \\
\hline$>3$ & 95 (7.9\%) & 81 (85.3\%) & $7(7.4 \%)$ & $7(7.4 \%)$ \\
\hline \multicolumn{5}{|c|}{ Family income (minimun wages) } \\
\hline$>2$ & $604(50.8 \%)$ & $530(87.7 \%)$ & $65(10.8 \%)$ & $9(1.5 \%)$ \\
\hline$\leq 2$ & $585(49.2 \%)$ & $490(83.8 \%)$ & $70(12.0 \%)$ & $25(4.3 \%)$ \\
\hline \multicolumn{5}{|c|}{ Residents in home (persons) } \\
\hline$\leq 4$ & $720(60.8 \%)$ & $625(86.8 \%)$ & $78(10.8 \%)$ & $17(2.4 \%)$ \\
\hline$>4$ & 464 (39.2\%) & $391(84.3 \%)$ & $56(12.1 \%)$ & $17(2.7 \%)$ \\
\hline \multicolumn{5}{|c|}{ Parents/caregivers level of education (years of study) } \\
\hline$>8$ & $772(64.5 \%)$ & $670(86.8 \%)$ & $87(11.3 \%)$ & $15(1.9 \%)$ \\
\hline$\leq 8$ & $425(35.5 \%)$ & $358(84.2 \%)$ & $48(11.3 \%)$ & $19(4.5 \%)$ \\
\hline \multicolumn{5}{|c|}{ Type of school } \\
\hline Private & $283(23.6 \%)$ & $252(89.0 \%)$ & $26(9.2 \%)$ & $5(1.8 \%)$ \\
\hline Public & 918 (76.4\%) & $780(85.0 \%)$ & 109 (1 1.9\%) & $29(3.2 \%)$ \\
\hline
\end{tabular}


The bivariate multinomial logistic regression model is shown in Table 3. Enamel fracture was not significantly associated to any independent variable. Severe trauma was significantly associated with sex, age, overjet, family income, and parents/caregivers level of education. Boys, older children, individuals with an overjet greater than $3 \mathrm{~mm}$, and individuals whose families had a lower income and parents/ caregivers with a lower level of education were more likely to present other trauma/trauma sequelae.
Table 4 shows the multivariate multinomial logistic regression. Sex, age, and overjet maintained a significant association with other trauma/trauma sequelae. Boys, older children, and individuals with an overjet $>3 \mathrm{~mm}$ were more likely to have other trauma/trauma sequelae. The association of family income and level of education and other trauma/trauma sequelae was attenuated and lost statistical significance $(p=0.085$; $\mathrm{p}=0.444$, respectively).

Table 2. Final estimation of variance components in the multilevel analysis ("null-model").

\begin{tabular}{lccccccc}
\hline Variable & Random effect & $\begin{array}{l}\text { Standard } \\
\text { deviation }\end{array}$ & Variance component & df & Chi-square & p-value & ICC ${ }^{a}$ \\
\hline Enamel fracture & INTRCPTI, UO (0) & 0.37681 & 0.14198 & 18 & 1.896 .379 & 0,394 & $0.04=4 \%$ \\
Other trauma/ trauma sequelae & INTRCPT1, UO (1) & 0.37834 & 0.14314 & 18 & 1.679 .525 & $>0,500$ & $0.04=4 \%$
\end{tabular}

antraclass correlation coefficient (ICC): fraction of the total variance that is due to the contextual level.

Table 3. Bivariate multinomial logistic regression model of factors associated with TDI ( $\mathrm{n}=1,201)$, Belo Horizonte, 2010.

\begin{tabular}{|c|c|c|c|c|}
\hline \multirow{4}{*}{ Variable } & \multirow{2}{*}{\multicolumn{2}{|c|}{ Enamel trauma $X$ no trauma }} & \multirow{2}{*}{\multicolumn{2}{|c|}{$\begin{array}{c}\text { Other trauma/ X No trauma } \\
\text { trauma sequelae }\end{array}$}} \\
\hline & & & & \\
\hline & Unadjusted OR & \multirow{2}{*}{ p-valor } & Unadjusted OR & \multirow{2}{*}{ p-valor } \\
\hline & $(95 \% \mathrm{Cl})$ & & $(95 \% \mathrm{Cl})$ & \\
\hline \multicolumn{5}{|l|}{ Sex } \\
\hline Female & 1.00 & & 1.00 & \\
\hline Male & $1.17(0.81-1.67)$ & 0.403 & $2.37(1.16-4.84)$ & 0.018 \\
\hline \multicolumn{5}{|l|}{ Age (years) } \\
\hline \multicolumn{5}{|l|}{8} \\
\hline \multicolumn{5}{|l|}{9} \\
\hline 10 & $1.16(0.93-1.46)$ & 0.192 & $1.92(1.19-3.10)$ & 0.008 \\
\hline \multicolumn{5}{|c|}{ Overjet (mm) } \\
\hline$\leq 3$ & 1.00 & & 1.00 & \\
\hline$>3$ & $0.65(0.29-1.43)$ & 0.647 & $3.04(1.29-7.21)$ & 0.011 \\
\hline \multicolumn{5}{|c|}{ Family income (minimum wages) } \\
\hline$>2$ & 1.00 & & 1.00 & \\
\hline$<2$ & $1.17(0.81-1.67)$ & 0.405 & $3.01(1.39-6.50)$ & 0.005 \\
\hline \multicolumn{5}{|c|}{ Residents in home (persons) } \\
\hline$\leq 4$ & 1.00 & & 1.00 & \\
\hline$>4$ & $1.15(0.80-1.65)$ & 0.461 & $1.60(0.81-3.17)$ & 0.179 \\
\hline \multicolumn{5}{|c|}{ Parents/caregivers' level of education (years of study) } \\
\hline$>8$ & 1.00 & & 1.00 & \\
\hline$\leq 8$ & $1.03(0.71-1.50)$ & 0.867 & $2.37(1.19-4.72)$ & 0.014 \\
\hline
\end{tabular}


Table 4. Multivariate multinomial logistic regression of factors associated with TDI ( $n=1,201$ ), Belo Horizonte, Brazil, 2010.

\begin{tabular}{|c|c|c|c|c|}
\hline \multirow{4}{*}{ Variables } & \multirow{2}{*}{\multicolumn{2}{|c|}{ Enamel trauma $X$ No trauma }} & \multirow{2}{*}{\multicolumn{2}{|c|}{$\begin{array}{c}\text { Other trauma/ X No trauma } \\
\text { trauma sequelae }\end{array}$}} \\
\hline & & & & \\
\hline & Adjusted OR & \multirow{2}{*}{ p-valor } & Adjusted OR & \multirow{2}{*}{ p-valor } \\
\hline & (95\%Cl) & & $(95 \mathrm{Cl})$ & \\
\hline \multicolumn{5}{|l|}{ Sex } \\
\hline Female & 1.00 & & 1.00 & \\
\hline Male & $1.19(0.83-1.71)$ & 0.344 & $2.34(1.13-4.84)$ & 0.021 \\
\hline \multicolumn{5}{|l|}{ Age (years) } \\
\hline \multicolumn{5}{|l|}{8} \\
\hline \multicolumn{5}{|l|}{9} \\
\hline 10 & $1.20(0.95-1.51)$ & 0.134 & $1.81(1.11-2.96)$ & 0.018 \\
\hline \multicolumn{5}{|c|}{ Overjet (mm) } \\
\hline$\leq 3$ & 1.00 & & 1.00 & \\
\hline$>3$ & $0.62(0.28-1.38)$ & 0.241 & $2.55(1.05-6.20)$ & 0.040 \\
\hline
\end{tabular}

OR: odds ratio; $95 \% \mathrm{Cl}$ : Confidence Interval at $95 \%$; adjusted by multinomial logistic regression method for all the variables listed in the table. For this analysis, the reference group was child without trauma.

\section{Discussion}

Since TDI in permanent teeth is most frequent in 8 to 10 -year-old individuals, ${ }^{1,5,6}$ representing a special risk group, this study was limited to this age group. Furthermore, they have distinct clinical characteristics as they have mixed dentition. The present study showed that children of 10 years of age also presented more trauma/trauma sequelae. As TDI is an accumulative event, a higher prevalence is expected in older children. This finding may also be explained by the longer exposure of teeth to reckless activities in this age group, increasing the liability to injuries. ${ }^{1,12,25,26}$

The results show a relatively high prevalence of TDI, when considering enamel fractures and other trauma/trauma sequelae in a single category. Among the observed TDI, the majority of cases was limited to enamel, corroborating the findings of previous epidemiological studies conducted in schools. ${ }^{27,28}$ This shows that the prevalence of TDI in the permanent dentition is higher when enamel fractures are included. Other trauma/ trauma sequelae, more visible and/or severe, are not only related to physical inabilities, such as pain and functional limitations, but it may also have psychosocial consequences and a negative impact on OHRQoL. Therefore, individuals affected by other trauma/trauma sequelae seek dental treatment more frequently. ${ }^{2,11,29}$
Differences regarding the associated factors of TDI involving enamel fracture or other trauma/trauma sequelae were also detected in the present study. While other trauma/trauma sequelae showed a significant association with sex, age, and overjet, enamel fracture was not associated with any of those variables. One could argue that minor occurrences on enamel could happen at any time regardless the aforementioned variables. For instance, enamel fractures may be associated with more simple factors, such as misuse of teeth with pencils and bottle caps or an accidental bite on hard food. ${ }^{30,31}$

As such, studies that include enamel fracture and other trauma/trauma sequelae as a single category of TDI and evaluate its consequences, such as treatment seeking, ${ }^{10}$ impact on OHRQoL, ${ }^{9,32,33,34}$ or even the relationship with associated factors, ${ }^{27}$ may not find a significant association between those variables and TDI. This may happen because enamel fracture is an outcome of higher prevalence compared to other trauma/trauma sequelae, ${ }^{14,35}$ and has a minor impact on the lives of the affected individuals and their families. 89,10,11,12

This study confirms that boys are more likely to be affected by TDI. This finding may be related to the fact that boys are more involved in acts of violence and engaged in sports and leisure activities. ${ }^{29,36}$ However, some authors emphasized that this difference has been reduced by the increased participation of girls in risky outdoor activities. ${ }^{4,5}$ 
The results of the present study showed that an overjet greater than $3 \mathrm{~mm}$ was a predisposing factor to other trauma/trauma sequelae. Indeed, an increased overjet is related to the proclination of anterior permanent teeth, which leads to an inadequate lip coverage. ${ }^{22}$ In the literature, the association between TDI and socioeconomic indicators is unclear. Our findings showed that children whose families earn less than two times the Brazilian minimum wage per month and have less than eight years of study were more likely to have other trauma/trauma sequelae in the bivariate analysis. Individuals with families with a lower income and lower level of education usually live in poorer areas, where leisure facilities are more deteriorated and unsafe, and the social environment is less supportive. ${ }^{26}$ However, socioeconomic status lost significance in the final model, demonstrating that children are subject to TDI, regardless of socioeconomic status.

Although no significant difference in the prevalence of TDI between children of public and private schools was found, this issue must be addressed. Children spend a significant amount of their time in the school and the discussion about healthy environments is thus important. Unsafe and overcrowded places facilitate falls and collisions and, therefore, have been considered a major factor related to TDI. Moreover, schools should be committed towards a more favorable social environment. They are considered an appropriate setting for health promotion for children through the encouragement of healthier habits and friendlier relationships. ${ }^{37}$

The present evaluation has limitations that should be acknowledged. The study was conducted in schools without the use of radiographs for the diagnosis of TDI. Therefore, the prevalence of this condition may have been underestimated due to undiagnosed root fractures, root resorptions, pulp necrosis, and pulp calcifications. In addition, the study has a cross-sectional design and, thus, the data do not support a causality relationship between the associated factors examined and TDI.

The results of the present study may be useful for practical purposes. Our findings suggest that enamel fracture should be considered a separate category of other trauma/trauma sequelae, especially when evaluating the consequences of the injury and in the identification of populations at higher risk of TDI. This strategy should be considered in the design and implementation of oral health public services. The present study demonstrates the need for the implementation of preventive and therapeutic strategies for individuals at risk for TDI as well as their families. Preventive strategies should also include the improvement of the environment where those individuals live.

Further studies using a stronger design, such as a case-control and longitudinal assessments will be required to entirely confirm the associations reported herein. Taking into account that the type of trauma may vary according to the place where the study is conducted, future evaluations should also be carried out in reference centers for TDI and emergency services in hospital settings, where other trauma/ trauma sequelae cases are more likely to be notified.

\section{Conclusion}

The prevalence of TDI in 8 to 10 -year-old schoolchildren was $14 \%$ but only $2.8 \%$ were other trauma/trauma sequelae. Differences regarding the associated factors of TDI involving enamel fracture or other trauma/trauma sequelae were detected, suggesting that these the two occurrences should not be evaluated as a single category.

\section{References}

\footnotetext{
1. Patel MC, Sujan SG. The prevalence of traumatic dental injuries to permanent anterior teeth and its relation with predisposing risk factors among 8-13 years school children of Vadodara city: an epidemiological study. J Indian Soc Pedod Prev Dent. 2012 Apr-Jun;30(2):151-7. https://doi.org/10.4103/0970-4388.99992
}

\author{
2. Bendo CB, Paiva SM, Abreu MH, Figueiredo LD, \\ Vale MP. Impact of traumatic dental injuries among \\ adolescents on family's quality of life: a population- \\ based study. Int J Paediatr Dent. 2014 Sep;24(5):387-96. \\ https://doi.org/10.1111/ipd.12083
}


3. Ramos-Jorge J, Paiva SM, Tataounoff J, Pordeus IA, Marques LS, Ramos-Jorge ML. Impact of treated/untreated traumatic dental injuries on quality of life among Brazilian schoolchildren. Dent Traumatol. 2014 Feb;30(1):27-31. https://doi.org/10.1111/edt.12048

4. Aldrigui JM, Jabbar NS, Bonecker M, Braga MM, Wanderley MT. Trends and associated factors in prevalence of dental trauma in Latin America and Caribbean: a systematic review and meta-analysis. Community Dent Oral Epidemiol. 2014 Feb;42(1):30-42. https://doi.org/10.1111/cdoe.12053

5. Oldin A, Lundgren J, Nilsson M, Norén JG, Robertson A. Traumatic dental injuries among children aged 0-17 years in the BITA study - a longitudinal Swedish multicenter study. Dent Traumatol. 2015 Feb;31(1):9-17. https://doi.org/10.1111/edt.12125

6. Atabek D, Alaçam A, Aydintuğ I, Konakoğlu G. A retrospective study of traumatic dental injuries. Dent Traumatol. 2014 Apr;30(2):154-61. https://doi.org/10.1111/edt.12057

7. Diangelis AJ, Andreasen JO, Ebeleseder KA, Kenny DJ, Trope $M$, Sigurdsson A et al.; International Association of Dental Traumatology. International Association of Dental Traumatology guidelines for the management of traumatic dental injuries: 1 . Fractures and luxations of permanent teeth. Dent Traumatol. 2012 Feb;28(1):2-12. https://doi.org/10.1111/i.1600-9657.2011.01103.x

8. Fakhruddin KS, Lawrence HP, Kenny DJ, Locker

D. Impact of treated and untreated dental injuries on the quality of life of Ontario school children. Dent Traumatol. 2008 Jun;24(3):309-13. https://doi.org/10.1111/j.1600-9657.2007.00547.x

9. Piovesan C, Abella C, Ardenghi TM. Child oral health-related quality of life and socioeconomic factors associated with traumatic dental injuries in school children. Oral Health Prev Dent. 2011;9(4):405-11.

10. Schuch HS, Goettems ML, Correa MB, Torriani DD, Demarco FF. Prevalence and treatment demand after traumatic dental injury in South Brazilian schoolchildren. Dent Traumatol. 2013 Aug;29(4):297-302. https://doi.org/10.1111/edt.12003

11. Bendo CB, Paiva SM, Varni JW, Vale MP. Oral health-related quality of life and traumatic dental injuries in Brazilian adolescents. Community Dent Oral Epidemiol. 2014 Jun;42(3):216-23. https://doi.org/10.1111/cdoe.12078

12. Chen Z, Si Y, Gong Y, Wang JG, Liu JX, He Y et al. Traumatic dental injuries among 8- to 12-year-old schoolchildren in Pinggu District, Beijing, China, during 2012. Dent Traumatol. 2014 Oct;30(5):385-90. https://doi.org/10.1111/edt.12110

13. Soriano EP, Caldas AF Jr, Góes PS. Risk factors related to traumatic dental injuries in Brazilian schoolchildren. Dent Traumatol. 2004 Oct;20(5):246-50. https://doi.org/10.1111/j.1600-9657.2004.00246.x

14. Damé-Teixeira N, Alves LS, Susin C, Maltz M. Traumatic dental injury among 12-year-old South Brazilian schoolchildren: prevalence, severity, and risk indicators. Dent Traumatol. 2013 Feb;29(1):52-8. https://doi.org/10.1111/j.1600-9657.2012.01124.x
15. Freire MC, Vasconcelos DN, Vieira AS, Araújo JA, Moreira RS, Nunes MF. Association of traumatic dental injuries with individual-, sociodemographic- and schoolrelated factors among schoolchildren in midwest Brazil. Int J Environ Res Public Health. 2014 Sep;11(9):9885-96. https://doi.org/10.3390/ijerph110909885

16. Martins MT, Sardenberg F, Abreu MH, Vale MP, Paiva SM, Pordeus IA. Factors associated with dental caries in Brazilian children: a multilevel approach. Community Dent Oral Epidemiol. 2014 Aug;42(4):289-99. https://doi.org/10.1111/cdoe.12087

17. Sardenberg F, Martins MT, Bendo CB, Pordeus IA, Paiva SM, Auad SM et al. Malocclusion and oral health-related quality of life in Brazilian school children. Angle Orthod. 2013 Jan;83(1):83-9. https://doi.org/10.2319/010912-20.1

18. Instituto Brasileiro de Geografia e Estatística. Cidades. Rio de Janeiro: Instituto Brasileiro de Geografia e Estatística; 2010 [cited 2016 Aug 21]. Available from: http://cod.ibge. gov.br/5N7

19. Cavalcanti AL, Bezerra PK, Alencar CR, Moura C. Traumatic anterior dental injuries in 7- to 12-year-old Brazilian children. Dent Traumatol. 2009 Apr;25(2):198-202. https://doi.org/10.1111/j.1600-9657.2008.00746.x

20. Andreasen JO, Andreasen FM, Andersson L. Textbook and color atlas of traumatic injuries to the teeth. 4th ed. Oxford: Blackwell Munksgaard; 2007.

21. Cons NC, Jenny J, Kohout FJ, Songpaisan Y, Jotikastira D. Utility of the dental aesthetic index in industrialized and developing countries. J Public Health Dent. 1989;49(3):163-6. https://doi.org/10.1111/j.1752-7325.1989.tb02054.x

22. Petti S. Over two hundred million injuries to anterior teeth attributable to large overjet: a meta-analysis. Dent Traumatol. 2015 Feb;31(1):1-8. https://doi.org/10.1111/edt.12126

23. Kirkwood B, Stern J. Essentials of medical statistics. 2nd ed. Oxford: Wiley-Blackwell; 2003.

24. Andersen RM, Davidson PL. Ethnicity, aging, and oral health outcomes: a conceptual framework. Adv Dent Res. 1997 May;11(2):203-9. https://doi.org/10.1177/08959374970110020201

25. Goettems ML, Torriani DD, Hallal PC, Correa MB, Demarco FF. Dental trauma: prevalence and risk factors in schoolchildren. Community Dent Oral Epidemiol. 2014 Dec;42(6):581-90. https://doi.org/10.1111/cdoe.12113

26. Soriano EP, Caldas Junior AF, Carvalho MVD, Amorim Filho HA. Prevalence and risk factors related to traumatic dental injuries in Brazilian schoolchildren. Dent Traumatol. 2007 Aug;23(4):232-40. https://doi.org/10.1111/j.1600-9657.2005.00426.x

27. Marcenes W, Murray S. Social deprivation and traumatic dental injuries among 14-year-old schoolchildren in Newham, London. Dent Traumatol. 2001 Feb;17(1):17-21. https://doi.org/10.1034/i.1600-9657.2001.170104.x

28. Shulman JD, Peterson J. The association between incisor trauma and occlusal characteristics in individuals 8-50 
years of age. Dent Traumatol. 2004 Apr;20(2):67-74. https://doi.org/10.1111/j.1600-4469.2004.00234.x

29. Cortes MI, Marcenes W, Sheiham A. Impact of traumatic injuries to the permanent teeth on the oral health-related quality of life in 12-14-year-old children. Community Dent Oral Epidemiol. 2002 Jun;30(3):193-8. https://doi.org/10.1034/j.1600-0528.2002.300305.x

30. Nicolau B, Marcenes W, Sheiham A. Prevalence, causes and correlates of traumatic dental injuries among 13-yearolds in Brazil. Dent Traumatol. 2001 Oct;17(5):213-7. https://doi.org/10.1034/j.1600-9657.2001.170505.x

31. Malikaew P, Watt RG, Sheiham A. Prevalence and factors associated with traumatic dental injuries (TDI) to anterior teeth of 11-13 year old Thai children. Community Dent Health. 2006 Dec;23(4):222-7.

32. Piovesan C, Antunes JL, Guedes RS, Ardenghi TM. Impact of socioeconomic and clinical factors on child oral health-related quality of life (COHRQoL). Qual Life Res. 2010 Nov; 19(9):1359-66. https://doi.org/10.1007/s11136-010-9692-7
33. Castro RA, Portela MC, Leão AT, Vasconcellos MT. Oral health-related quality of life of 11 - and 12-yearold public school children in Rio de Janeiro. Community Dent Oral Epidemiol. 2011 Aug;39(4):336-44. https://doi.org/10.1111/i.1600-0528.2010.00601.x

34. Feldens CA, Day P, Borges TS, Feldens EG, Kramer PF. Enamel fracture in the primary dentition has no impact on children's quality of life: implications for clinicians and researchers. Dent Traumatol. 2016 Apr;32(2):103-9. https://doi.org/10.1111/edt.12222

35. Tovo MF, Santos PR, Kramer PF, Feldens CA, Sari GT. Prevalence of crown fractures in 8-10 years old schoolchildren in Canoas, Brazil. Dent Traumatol. 2004 Oct;20(5):251-4. https://doi.org/10.1111/j.1600-9657.2004.00253.x

36. Glendor U. Epidemiology of traumatic dental injuries: 12 year review of the literature. Dent Traumatol. 2008 Dec;24(6):603-11. https://doi.org/10.1111/j.1600-9657.2008.00696.x

37. Moysés ST, Moysés SJ, Watt RG, Sheiham A. Associations between health promoting schools' policies and indicators of oral health in Brazil. Health Promot Int. 2003 Sep;18(3):209-18. https://doi.org/10.1093/heapro/dag016 